\title{
High Prevalence of Altered Immunological Biomarkers in a Transgender Population
}

\author{
Ramos SG ${ }^{1 *}$, Ingenito $F^{1}$, Mormandi EA², Nagelberg AJ², Otero $\mathrm{PM}^{2}$, Lessa $\mathrm{CF}^{1}$, and Carballo \\ $\mathbf{O G}^{1}{ }_{1}$ Immunology Laboratory, Immunology and Histocompatibility Unit, Carlos G Durand Hospital, Argentina \\ ${ }^{2}$ Endocrinology Laboratory, Endocrinology Section, Carlos G Durand Hospital, Argentina
}

"Corresponding author: Ramos SG, Immunology Laboratory, Immunology and Histocompatibility Unit, Carlos G Durand Hospital, Buenos Aires, Argentina, E-mail: sgramos58@hotmail.com

Received: 12 Dec, 2019 | Accepted: 15 Jan, 2020 | Published: 24 Jan, 2020

Citation: Ramos SG, Ingenito F, Mormandi EA, Nagelberg AJ, Otero PM, et al. (2020) High Prevalence of Altered Immunological Biomarkers in a Transgender Population. Autoimmun Infec Dis 3(1): dx.doi.org/10.16966/2470-1025.125

Copyright: (c) 2020 Ramos SG, et al. This is an open-access article distributed under the terms of the Creative Commons Attribution License, which permits unrestricted use, distribution, and reproduction in any medium, provided the original author and source are credited.

\section{Introduction}

It has been shown that sex, and the steroids associated with it, are factors that significantly influence various aspects of the immune system [1-5].

The importance of the interaction of the immune and endocrine systems is reflected during situations such as pregnancy, autoimmune diseases and some infectious diseases. In all cases there is evidence that sex steroids have an important role as immunoregulators. Although much remains to be clarified, it is now known that these hormones can regulate different processes involved in the immune response, including the maturation and selection of thymocytes, cell transit, the expression of molecules and receptors of the major histocompatibility class II complex, the proliferation of lymphocytes and the production of cytokines [1-5]. Cells belonging to the immune system are delicately regulated by molecules secreted by themselves, but they are also susceptible to regulation by hormones, neurohormones and/or neurotransmitters.

Females of different species produce higher levels of circulating immunoglobulins and have a more pronounced humoral immune response in infections. The production of a variety of autoreactive antibodies is also more frequent in females. It has been shown that estrogens increase the B cell response both "in vivo" and "in vitro", while androgens and progesterone decrease the production of antibodies. However, the mechanisms by which these hormones influence these processes are not known in depth. According to these observations, it is suggested that estrogens enhance B cell-mediated immunity and suppress some aspects dependent on T lymphocytes. Testosterone seems to suppress both the $\mathrm{T}$ and $\mathrm{B}$ responses [8-11]. Of all the range of hormones that make up the neuroendocrine system, sex steroids are important modulators of immune function [1-5].

The relationship between autoimmune diseases and sex hormones is well documented [6]. The human immune system exhibits sexual dimorphism, with predominance in the female sex of autoimmune diseases. Female sex steroids are strongly involved in the mediation of that immune dimorphism, in part because estrogen accentuates the disease in several models of autoimmunity. Therefore, sex steroids can influence the breakdown of tolerance inducing autoimmune disease [7].

Anti-Nuclear Antibodies (ANA) are measurable in approximately $31.7 \%$ of the population in cut-off titles of $1 / 40,13.3 \%$ in titles of $1 / 80,5 \%$ in titles, $1 / 160$ and $3.3 \%$ in titles of $1 / 320$ using HEp-2 cells as an antigenic substrate [12]. The reference values established in our Immunology laboratory in a population of 100 blood donors (unpublished data) agree with the published data.

Some patients with viral infections or under treatment with some medication may have transiently positive ANA, as well as can be found in patients with cancer [13].

Likewise, autoantibodies to low titles could also be the result of a true autoimmune reaction and should not be interpreted as having low or no clinical significance [12]. For all the above, it is crucial to take the positive values in the clinical context, considering that some autoimmune diseases would be strongly associated with ANA, this being an important diagnostic criterion. The patterns presented by these antibodies should be specific for these diseases, such as, for example, nucleolar pattern or centromeric nuclear pattern, in scleroderma and CREST syndrome, ("CREST" refers to the five main features: calcinosis, Raynaud's phenomenon, esophageal dysmotility, sclerodactyly, and telangiectasia), respectively.

Most individuals with positive ANA do not have an autoimmune disease and are unlikely to develop one, because the prevalence of all autoimmune disorders is $5 \%$ to $7 \%$ [14]. In addition, the disease that is most closely linked to ANA positivity, Systemic Lupus Erythematosus (SLE), is relatively rare, affecting no more than 1 to 1.5 per 1,000 people $(0.1$ to $0.15 \%)$ in the United States [15]. However, if the ANA positivity is for all practical purposes, a requirement for the diagnosis of autoimmune disease, it must also be assumed that 
individuals who are in preclinical stages of the disease are represented in the positive ANA of the general healthy population. Although many consultations for ANA positivity seen in immunological practice are not associated with any identifiable pathology, it is also true that for early detection it will be necessary to focus on the positive ANA population. The possibility that other serum markers could be used to differentiate benign ANA positivity from what carries a high risk of autoimmune disease has been considered. These markers can include other autoantibodies, since it is well known that the positivity of autoantibodies increases in quantity and complexity according to the years that precede a diagnosis of SLE [16].

A case has been described of a transgender woman with sexual reassignment surgery and the subsequent development of Lupus Erythematosus Tumidus (LET). This report emphasizes the triggers, including prolonged exposure to significant doses of estrogen as part of sex reassignment surgery, which can lead to the development of lupus in a genetically predisposed individual [17]. Another case has been reported of a transgender woman patient who developed systemic lupus erythematosus after 20 years of Hormone Therapy (HT) with estrogens [18]. A similar case was published with the development of autoimmune hepatitis associated with estrogen and antiandrogen therapy [19]. However, as concluded in a 2015 cross-HT review, the absolute risk of these effects in the human population is likely to be small and difficult to detect due to the low number of transgender patients in clinical studies [20].

Gender identity disorder is defined as a strong and persistent cross-sex identification that is associated with a significant concern of living in an incongruous gender (gender dysphoria). Therefore, transgender people often request hormonal therapy and, finally, surgery, to modify their physical appearance and affirm the sex with which they identify [21].

The knowledge of the mechanism of action and the adverse effects of cross-HT with respect to biological sex applied to transgender individuals is limited mainly by the low number of subjects treated in each center, the lack of prospective studies and the wide variety of therapeutic schemes used. The administration of high doses of estrogens or androgens for long periods of time, as well as procedures such as silicone breast implants, mastectomies, cosmetic and dermatological treatments, could contribute to the appearance of autoimmunity and alterations in humoral immunity in healthy individuals [22]. So, we believe that transgender people of healthy biological male and female sex provide us with a unique opportunity to study the in vivo effects of cross-HT on the immune system.

The cross-HT of transgender people aims to suppress the secondary sexual characteristics of the original gender and allow the development of those that correspond to the desired gender to the greatest extent possible while respecting physiological hormone levels.

In this work, biomarkers of autoimmunity and humoral immunoproteins were studied in healthy transgender individuals under evaluation to receive cross-HT.

\section{Materials and Methods}

Individuals who consulted to change sex in the Group for the Care of Transgender People (GAPET), Buenos Aires, Argentina, were included in the study. We also studied a control group of 100 blood donors.

The following autoantibodies were determined: anti-thyroid antibodies, anti-thyroperoxidase and anti-thyroglobulin (aTPO and aTg) by chemiluminescence (INMULITE 2000, SIEMENS), Anti-
Nuclear Antibodies (ANA) by indirect Immunofluorescence (IFI) using HEp-2 cells as substrate (BIORAD Kallestad), anti-extractable nuclear antigens (anti-Ro/SSA, anti-La/SSB, anti-Sm, anti-U1snRNP) by Enzyme-Linked Immunosorbent Assay (ELISA INOVA screening method) and by linear immunoassay (LIA IMTEC confirmatory method), Anti-Mitochondrial (AMA), Anti-Smooth Muscle (ASMA), Anti-Gastric Parietal Cells (APCA), Anti-Liver Kidney Microsomal (LKM) all isotypes IgG by IFI using as substrate liver, kidney and rat stomach (BIOCIENTIFIC), anti-cardiolipin (IgG/IgM), anti- $\beta 2$ glycoprotein I (IgG/IgM) by INOVA ELISA. The quantification of immunoglobulins (IgG, IgA, IgM), and complement fractions $\mathrm{C} 3$ and $\mathrm{C} 4$ was performed by nephelometry (MININEPHPLUS the binding site).

\section{The following criteria for the inclusion of patients were used:}

a) Without treatment (WT): without having initiated the cross-HT in our Institution

b) In treatment (T): in cross-HT in our Institution

c) Signature of informed consent to participate in the GAPET studies

\section{The exclusion criteria were:}

a) Gonadectomized patients, were excluded because in the study period they were studied in very low numbers

b) Positive serology for human immunodeficiency virus (HIV) and hepatotropic virus (HBV, HCV)

c) Patients with pathologies that contraindicate the eventual treatment with sexual steroids following the international recommendations (2012. Standards of Care for the Health of Transsexual, Transgender, and Gender-Nonconforming People, Version 7. International Journal of Transgenderism, 13(4), 165-232).

Hormone treatment in transgender women $(\mathrm{Tg}-\mathrm{W})$ was estradiol valerate $(2-4 \mathrm{mg} /$ day $)$ orally or 17 beta-estradiol $(3 \mathrm{mg} /$ day $)$ transdermally, with or without the addition of cyproterone acetate (25-100 mg/day) orally.

The hormonal treatment in transgender men (Tg-M) was testosterone $(50 \mathrm{mg} /$ day) transdermal gel or testosterone undecanoate (1,000 mg/3 months) intramuscularly.

We included 146 patients (59 Tg-M (age $=29 \pm 10$ years) and 87 $\mathrm{Tg}-\mathrm{W}$ (age $=32 \pm 11$ years) who met the inclusion and exclusion criteria of the study. The Microsoft $\odot$ Excel program was used to design the database. For the statistical analysis (obtaining average and standard deviation, prevalence), Microsoft $\odot$ Excel was used. Together, the data was analyzed with SPSS Statistics $17.0 \odot$. They were reported as mean \pm standard deviation, as a level of significance a $\mathrm{p}<0.05$ was considered valid.

\section{Results}

$27 / 87 \mathrm{Tg}-\mathrm{W}(31 \%)$ and $21 / 59 \mathrm{Tg}-\mathrm{M}(36 \%)$ resulted in positive ANA ( $p>0.05$ between both groups). The difference was highly significant when compared with the positivity rate reported by Tan and collaborators in Normal Controls (NC) 13.3\% at cut-off value 1/80 12 and with our own NC, $13 \%(\mathrm{p}<0.05)$.

Of the total of the specific autoantibodies studied, we found positivity in 20/87 $\mathrm{Tg}-\mathrm{W}(23 \%)$ and in 19/59 (32\%) Tg-M (p>0.05). Comparing with the positivity of specific antibodies obtained in our controls as an average not exceeding $5 \%$, these values found in the transgender population were statistically highly significant $(\mathrm{p}<0.001)$ in both groups. 
We found a positivity of ANA plus specific autoantibodies of 50/87 (57\%) in $\mathrm{Tg}-\mathrm{W}$ and $40 / 59$ (68\%) in $\mathrm{Tg}-\mathrm{M}$. The Tg-M had greater positivity of autoantibodies than the $\mathrm{Tg}-\mathrm{W}$, this difference being significant $\mathrm{p}=0.012$.

We did not find a significant difference in the concentration of Immunoglobulins (Igs) in both transgender groups ( $p>0.05$ ), although there was a higher concentration tendency in all immunoglobulins in the Tg-M group. We found two patients in the Tg-W group with absolute IgA deficiency. The concentration of complement factors C3 and $\mathrm{C} 4$ were within normal limits, with no differences between the groups studied $(\mathrm{p}>0.05)$ (Table 1).

Twenty-seven of 87 transgender of the $\mathrm{Tg}-\mathrm{W}$ group reported having performed cross-HT self-treatment, 24/87 were subjected to silicone breast implants, definitive laser hair removal, use of excessive makeup and other dermatological and cosmetic interventions.

When analyzing the transgender population according to whether they received cross-HT (T) compared to those who had not started treatment in our institution (WT) we found the results shown in figures 1 and 2. Tables 2 and 3 show the ANA titles found in both transgender populations.

\section{Discussion and Conclusion}

The detection of autoimmune disease in the early or preclinical stage is clinically important since it is known that the institution of treatment before the onset of organ damage has a greater chance of improving the disease [23]. However, the early and reliable diagnosis of an autoimmune disease is a challenge, largely due to the profiles of available diagnostic tests. The optimal test would be sensitive enough to detect all people who have a disease, and at the same time with enough specificity to predict the probable disease. The presence of anti- nuclear antibodies in serum is a common denominator of many autoimmune diseases. This test is performed by indirect immunofluorescence using HEp-2 culture cells as a substrate [24].

ANA positivity is for all practical purposes necessary to make a diagnosis of lupus since $99 \%$ of SLE patients having significant levels of this antibody detected at some point during the course of the disease. This antibody also appears positive in $60 \%$ to $80 \%$ of scleroderma, $100 \%$ of mixed connective tissue disease, $61 \%$ of polymyositis/ dermatomyositis, $52 \%$ of rheumatoid arthritis, $40 \%$ to $70 \%$ of Sjögren's syndrome [25], and in varying percentages in: Hashimoto's thyroiditis, Graves' disease and autoimmune hepatitis [26].

Table 1: Demographic data and results of transgender women, transgender men and controls.

\begin{tabular}{|c|c|c|c|c|c|}
\hline & Tg-W & Tg-M & $\mathbf{P}$ & Nc & $\mathbf{P}$ \\
\hline n & 87 & 59 & & 100 & \\
\hline Age (years) & $32 \pm 11$ & $29 \pm 10$ & ns & $35 \pm 10$ & ns \\
\hline ANA(HEp-2)+>1/80 & $27 / 87(31 \%)$ & $21 / 59(36 \%)$ & ns & $13 / 100(13 \%)$ & $<0,001$ \\
\hline \multicolumn{6}{|c|}{ Specific Autoantibodies } \\
\hline a-SSA/Ro & $1 / 87(1 \%)$ & $1 / 59(2 \%)$ & ns & $0 / 100(0 \%)$ & \\
\hline a-SSB/La & $0 / 87(0 \%)$ & $2 / 59(3 \%)$ & ns & $0 / 100(0 \%)$ & \\
\hline a-Sm & $0 / 87(0 \%)$ & $0 / 59(0 \%)$ & ns & $0 / 100(0 \%)$ & \\
\hline a-RNP & $0 / 87(0 \%)$ & $0 / 59(0 \%)$ & ns & $0 / 100(0 \%)$ & \\
\hline a-AMA & $0 / 87(0 \%)$ & $1 / 59(2 \%)$ & ns & $0 / 100(0 \%)$ & \\
\hline a-ASMA & $6 / 87(7 \%)$ & $5 / 59(8 \%)$ & ns & $0 / 100(0 \%)$ & \\
\hline a-APCA & $1 / 87(1 \%)$ & $0 / 59(0 \%)$ & ns & $1 / 100(1 \%)$ & \\
\hline a-LKM & $0 / 87(0 \%)$ & $0 / 59(0 \%)$ & ns & $0 / 100(0 \%)$ & \\
\hline a-CCP & $0 / 87(0 \%)$ & $0 / 59(0 \%)$ & ns & $0 / 100(0 \%)$ & \\
\hline a-TPO & $9 / 87(10 \%)$ & 9/59 (15\%) & ns & $1 / 100(1 \%)$ & \\
\hline a-CARDIOLIPIN-IgG & $0 / 87(0 \%)$ & $0 / 59(0 \%)$ & ns & $1 / 100(1 \%)$ & \\
\hline a-CARDIOLIPIN-IgM & $0 / 87(0 \%)$ & $0 / 59(0 \%)$ & ns & $1 / 100(1 \%)$ & \\
\hline a- $\boldsymbol{\beta 2 - G L Y C O P R O T E I N ~ I - I g G ~}$ & $0 / 87(0 \%)$ & $1 / 59(2 \%)$ & ns & $1 / 100(1 \%)$ & \\
\hline a-ß2-GLYCOPROTEIN I-IgM & $3 / 87(3 \%)$ & $0 / 59(0 \%)$ & ns & $0 / 100(0 \%)$ & \\
\hline Total specific autoAb & $20 / 87(23 \%)$ & $19 / 59(32 \%)$ & ns & $5 / 100(5 \%)$ & $<0,001$ (\#) \\
\hline Total specific autoAb+ANA+ & $50 / 87(57 \%)$ & $40 / 59(68 \%)$ & ns & $18 / 100(18 \%)$ & $<0,001(\&)$ \\
\hline \multicolumn{6}{|c|}{ Immunoglobulins } \\
\hline $\operatorname{lgG}(\mathrm{mg} / \mathrm{dl})$ & $1415 \pm 341$ & $1467 \pm 323$ & ns & $849-1810$ & ns \\
\hline $\operatorname{lgA}(\mathrm{mg} / \mathrm{dl})$ & $265 \pm 111$ & $272 \pm 105$ & ns & $70-350$ & ns \\
\hline $\operatorname{lgM}(\mathrm{mg} / \mathrm{dl})$ & $129 \pm 73$ & $177 \pm 84$ & ns & $50-275$ & ns \\
\hline IgA deficiency<17 mg/dl) & $2 / 87$ & & & & \\
\hline $\operatorname{lgG}(\mathrm{mg} / \mathrm{dl})>2000$ & & $4(7 \%)$ & & & \\
\hline $\operatorname{lgA}(\mathrm{mg} / \mathrm{dl})>400$ & & $8(13 \%)$ & & & \\
\hline \multicolumn{6}{|l|}{ Complement } \\
\hline C3 (mg/dl) & $139 \pm 39$ & $145 \pm 38$ & ns & $83-177$ & ns \\
\hline $\mathrm{C} 4$ (mg/dl) & $26 \pm 9$ & $29 \pm 10$ & ns & $16-47$ & ns \\
\hline
\end{tabular}

Tg-W: Transgender Women, Tg-M: Transgender Men, n: Number of transgender and control studied, ANA: Anti Nuclear Antibodies, ns: Not Significant. (\#) $p<0.01$ when using the stringent Bonferroni correction for multiple testing however, a corrected P-value of 0.01 represents significance.

(\&) $p<0.0033$ when using the stringent Bonferroni correction for multiple testing however, a corrected P-value of 0.0033 represents significance. 

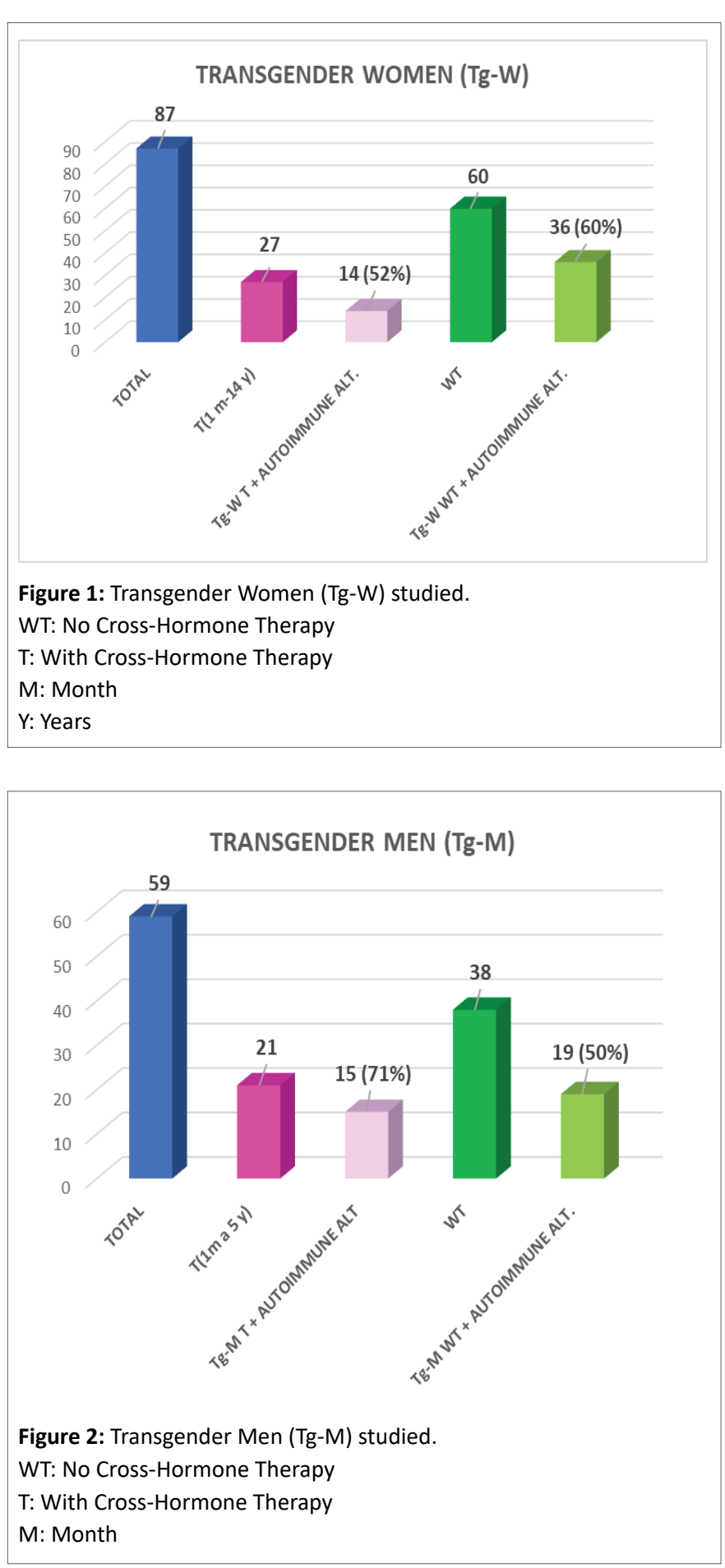

Although the negative predictive value of this antibody is high, there are few quantitative and objective measures available to establish the prognosis for a person with a positive ANA.

This contrasts with the tools that are available for the determination of the risk of cardiovascular disease, where multiple profiles that include personal and family history, social habits, body measurements and laboratory tests can generate a prediction of reasonable risk and very customized for an individual patient [27]. In practice, doctors use some profiles to assess the risk associated with positive ANA. Young women are more likely to develop autoimmune diseases than men, so ANA positivity in these is of greater concern. This result is
Table 2: Transgender women (Tg-W) studied. According to the title of ANA.

\begin{tabular}{|l|c|}
\hline \multicolumn{2}{|c|}{ Transgender women (Tg-W) } \\
\hline Total & 87 \\
\hline ANA positive & 27 \\
\hline Title 1:80 & 6 \\
\hline Title 1:160 & 8 \\
\hline Title 1:320 & 10 \\
\hline Title 1:640 & 2 \\
\hline Title 1:1280 & 1 \\
\hline
\end{tabular}

Table 3: Transgender men (Tg-M) studied. According to the title of ANA.

\begin{tabular}{|l|c|}
\hline \multicolumn{2}{|c|}{ Transgender Men (Tg-M) } \\
\hline Total & 59 \\
\hline ANA positive & 21 \\
\hline Títle 1:80 & 7 \\
\hline Títle 1:160 & 5 \\
\hline Títle 1:320 & 8 \\
\hline Títle 1:640 & 1 \\
\hline Títle 1:1280 & 0 \\
\hline
\end{tabular}

also consistent with other findings in healthy control populations including a study of 500 individuals showing that ANA positivity was almost twice as frequent in women as in men [28].

In the transgender population that we investigated through a crosssectional analysis there are many reasons for ANA positivity. Other clues are available to suggest approaches to stratify risk in the ANApositive population. One would be the presence of other autoantibodies that accumulate before the diagnosis of autoimmune disease [10]. The prevalence of any of these is low, however.

There are many environmental factors acting and this represents the various external agents that act synergistically with other deleterious effects to increase autoimmunization. For example, it is considered that environmental agents, traumatisms, infections, hormones, silicone implants, cosmetic treatments, etc., can initiate autoimmune processes that culminate in immunopathological events manifested by symptoms that are added to the diagnostic criteria of autoimmune disease.

According to the results obtained, we observed a high prevalence of altered immunological biochemical markers in the studied transgender population.

In the $\mathrm{Tg}-\mathrm{W}$ population, we found the same autoimmune alterations in those with cross-HT 14/27 (52\%) and those not treated 36/60 (60\%) $\mathrm{p}>0.05$, perhaps due to the different doses used, duration of therapy and unregistered hormonal self-treatment.

In the $\mathrm{Tg}-\mathrm{M}$, we found autoimmune alterations with a very significant difference between those treated with cross-HT 15/21 (71\%) and those not treated 19/38 (50\%) $\mathrm{p}<0.05$.

The previous aesthetic procedures (surgeries, permanent hair removal, excessive use of cosmetic products, silicone prosthesis and injection of methacrylate and self-administered cross-hormonal treatments), predispose them to the formation of autoantibodies due to loss of tolerance and alteration of the immune response to different antigenic stimuli.

The treatment of transgender people should have a multidisciplinary approach, should not be limited to the doctor (hormonal and sex 
reassignment surgery), but the intervention should be extended to other disciplines. Due to the results found in this study, we believe that immunological study is essential for the follow-up of individuals who are at risk of developing immune alterations because of the hormonal treatment instituted in each case. Within this multidisciplinary framework we suggest carrying out an immunological follow-up as part of the care protocol before and during the process of sex reassignment and, probably, for life, given that the hormonal treatment is undefined and, in addition, can cause multiple long-term adverse effects.

There are no previous studies in humans that demonstrate the effect of the use of hormones on the immune system especially in transgender individuals, nor on the response of autoantibodies to the administration of estrogen in the form of oral or injectable contraceptives as cross-hormone therapy.

It would be important to perform longitudinal studies to determine the evolution of the autoimmune response and if the appearance of autoantibodies translates into autoimmune disease.

\section{References}

1. Barañao RI (2009) Hormonas sexuales y respuesta inmunológica. Revista SAEGRE XVI-NN2.

2. Bouman A, Heineman MJ, Faas MM (2005) Sex hormones and the immune response in humans. Hum Reprod Update 11: 411-423.

3. Cutolo M, Sulli A, Capellino S, Villaggio B, Montagna P, et al. (2004) Sex hormones influence on the immune system: basic and clinical aspects in autoimmunity. Lupus 13: 635-638.

4. Zandman Goddard G, Peeva E, Shoenfeld Y (2007) Gender and autoimmunity. Autoimmun Rev 6: 366-372.

5. Geffner J, Fainboim L (2005) Introducción a la Inmunología Humana. 5 a edicion, Buenos Aires, Editorial Médica Panamericana, SA.

6. Lee TP, Chiang BL (2012) Sex differences in spontaneous versus induced animal models of autoimmunity. Autoimmun Rev 11: A422-A429.

7. Hughes GC, Clark EA (2007) Regulation of dendritic cells by female sex steroids: relevance to immunity and autoimmunity. Autoimmunity 40: 470-481.

8. Grossman C (1989) Possible underlaying mechanism of sexual dimorphism in the immune response, fact and hypothesis. J Steroid Biochem 34: 241-251.

9. Bebo BF, Schuster JC, Vandenbark AA, Offner H (1999) Androgens alter the cytokine profile and reduce encephalitogenicity of myelinreactive T cells. J Immunol 162: 35-40.

10. Da Silva JA (1999) Sex hormones and glucocorticoids: interactions with the immune system. Ann N Y Acad Sci 876: 102-118.

11. Olsen NJ, Kovacs WJ (2001) Effects of androgens on T and B lymphocyte development. Immunol Res 23: 281-288.

12. Tan EM, Feltkamp TE, Smolen JS, Butcher B, Dawkins R, et al. (1997) Range of antinuclear antibodies in healthy individuals. Arthritis Rheum 40: 1601-1611.
13. Shoenfeld Y, Isenberg DA (1989) Aging and Autoimmunity. In: The mosaic of autoimmunity, New York, Elsevier.

14. Davidson A, Diamond B (2001) Autoimmune diseases. N Engl J Med 345: $340-350$

15. Chakravarty EF, Bush TM, Manzi S, Clarke AE, Ward MM (2007) Prevalence of adult systemic lupus erythematosus in California and Pennsylvania in 2000: estimates obtained using hospitalization data. Arthritis Rheum 56: 2092-2094.

16. Arbuckle MR, McClain MT, Rubertone MV, Scofield RH, Dennis GJ, et al. (2003) Development of autoantibodies before the clinical onset of systemic lupus erythematosus. N Engl J Med 349: 1526-1533.

17. Gisele Zandman-Goddard, Michal Solomon, Aviv Barzilai, Yehuda Shoenfeld (2007) Lupus erythematosus tumidus induced by sex reassignment surgery. J Rheumatol 34: 1938-1940.

18. Chan KL, Mok CC (2013) Development of systemic lupus erythematosus in a male-to-female transsexual: the role of sex hormones revisited. Lupus 22: 1399-1402.

19. Tangpricha V, Afdhal NH, Chipkin SR (2001) Case Report: Autoimmune Hepatitis in a Male-to-Female Transsexual Treated with Conjugated Estrogens. The International Journal of Transgenderism 5.

20. Gooren LJ, Kreukels B, Lapauw B, Giltay EJ (2015) (Patho) physiology of cross-sex hormone administration to transsexual people: The potential impact of male-female genetic differences. Andrologia 47: 5-19.

21. Vita R, Settineri S, Liotta M, Benvenga S, Trimarchi F (2018) Changes in hormonal and metabolic parameters in transgender subjects on cross-sex hormone therapy: A cohort study. Maturitas 107: 92-96.

22. Bentkover SH (2009) The biology of facial fillers. Facial Plast Surg 25: 73-85.

23. Sisó $A$, Ramos-Casals $M$, Bové $A$, Brito-Zerón $P$, Soria $N$, et al. (2008) Previous antimalarial therapy in patients diagnosed with lupus nephritis: influence on outcomes and survival. Lupus 17: 281-288.

24. Meroni PL, Schur PH (2010) ANA screening: an old test with new recommendations. Ann Rheum Dis 69: 1420-1422.

25. Lahita RG, Chiorazzi N, Reeves WH (2000) Textbook of the Autoimmune diseases. Lippincott Williams and Nilkins, Philadelphia.

26. Czaja AJ, Nishioka M, Morshed SA, Hachiya T (1994) Patterns of nuclear immunofluorescence and reactivities to recombinant nuclear antigens in autoimmune hepatitis. Gastroenterology 107: 200-207.

27. Sheridan S, Pignone M, Mulrow C (2003) Framingham-based tools to calculate the global risk of coronary heart disease: a systematic review of tools for clinicians. J Gen Intern Med 18: 1039-1052.

28. Fernandez SA, Lobo AZ, Oliveira ZN, Fukumori LM, Périgo AM, et al. (2003) Prevalence of antinuclear autoantibodies in the serum of normal blood donors. Rev Hosp Clin Fac Med Sao Paulo 58: 315-319. 